\title{
Lecturers' perceptions: The value of assessment rubrics for informing teaching practice and curriculum review and development
}

\section{Bharuthram, Sharita}

\begin{abstract}
The assessment rubric is increasingly gaining recognition as a valuable tool in teaching and learning in higher education. While many studies have examined the value of rubrics for students, research into the lecturers' usage of rubrics is limited. This article explores the lecturers' perceptions of rubrics, in particular, its use and design, the role it can play in informing one's teaching practice and in curriculum review and development. The data shows that many lecturers use the rubric in a very mechanical and unconscious manner and view it mostly as a grading tool with limited instructional value. While acknowledging the rubric as a reflective tool for students, lecturers do not perceive it as having the same benefits for them. The findings, therefore suggest more conversations around the role that rubrics can play in informing one's teaching practice and course design. It also suggests further research into this area.
\end{abstract}

\section{Introduction}

Assessment is an integral component in the teaching and learning process. In recent years, as a result of the changing context of higher education in South Africa, more emphasis has been placed for lecturers to make their assessment practices transparent to students. Furthermore, as a result of the move towards outcome-based education and a learner-centred approach to teaching, students are becoming more empowered and are demanding more transparency on the relevance of assessment tasks and how these will be assessed (Lombardi and Oblinger 2008). The rubric is one tool that is being used by lecturers across the higher education spectrum to make assessment tasks more authentic and to demystify the learning process (Owens 2005). While there are slight differences in the literature in the way rubrics are defined, there is general consensus that a rubric that is well constructed will identify the criteria that will be used to judge the assessment task, gradations of quality linked to each criteria, as well as the performance levels (Andrade, Du and Mycek 2010; Reddy and Andrade 2010; Arter and Chappius 2007). While some literature speaks against rubrics, see for example, Wilson (2006), who argues that rubrics are too artificial, rigid and formulaic, and Chapman and Inman (2009), who fear that rubrics may restrict problem solving, decision-making and creativity, more has been written in favour of rubrics. Researchers both locally (Lombard 2011; McKenna 2007) and internationally (Reddy and Andrade 2010; Gallavan and Kottler 2009; Cooper and Gargan 2009; Reddy 2007; Schneider 2006; Andrade and Du 2005) have acknowledged that rubrics have potential benefits for both the lecturer/assessor and the student. For example, Cooper and Gargan (2009) argue that rubrics lead to deeper levels of thinking during their design stage as the lecturer attempts to align the outcomes of a particular section with the assessment task. Rubrics also assist in making marking easier and more objective (Gezie et al. 2012). Additionally, some researchers suggest that the rubric could be a useful tool to provide feedback on work in progress (for example, Lombard 2011) and that rubrics can also help students become more active learners and improve their performance (Andrade and Du 2005). 
While there is an abundance of literature on students' perceptions on the use of rubrics, the literature on the usefulness of rubrics from the perspective of the lecturer/ assessor with a particular focus on course delivery and course design, especially in the South African context, is scarce. Hence, this research attempts to address this gap by examining the value that rubrics have for lecturers, both in terms of the impact, if any that it may have on their teaching practice as well as in curriculum development. In doing so, this article also addresses the manner in which rubrics are designed and used by a group of lecturers at a higher education institution in South Africa. Some of the challenges experienced by these lecturers when using rubrics are also discussed. The theoretical foundation that underpins this research is social constructivism, which sees the learner as 'central in the creation of meaning ...' (Biggs 1996, 348). In order to work within a learner-centred framework, instructional designers have emphasized 'alignment between the objectives of a course and the targets for assessing student performance' (Biggs 1996, 347). To this end, Biggs (1996) coined the term constructive alignment, which begins with what the lecturer intends for the student to learn and the intended standards, i.e. the intended learning outcomes (ILOs). The ILO statement should contain a verb that indicates what the relevant activities are that students need to undertake in order to attain the ILO, for example, using task words such as describe, explain and illustrate. The teaching and learning activities and the assessment tasks should then be aligned to the ILOs. In this way learning is constructed by the activities that students are given and the assessment focuses on how well students have achieved the outcomes (Biggs and Tang 2009). To this end, a clearly defined grading criteria (rubric) will assist students in achieving the expectations of the lecturer and invariably the ILOs. However, it is essential that the lecturer/assessor has a clear idea of the ILOs and the criteria for measuring the outcome in order to be able to construct a good rubric.

\section{Providing a context}

In the year 2009 the university where this research was conducted embarked on developing its strategic institutional operating plan for the next five years (IOP 20102014). As part of its IOP: 2010-2014, the university developed a comprehensive strategic plan for teaching and learning accompanied by a Charter of a University graduate. Amongst others, the strategic plan places great emphasis on assessment practices. To this end, a series of seminars/workshops are being held on a regular basis for academic staff on teaching and learning issues including assessment practices with a focus on constructive alignment. Related to the notion of constructive alignment is the making of assessment tasks explicit for students through the use of rubrics. While there is a growing number of academics who are familiar with rubrics and do actually make use of them, no research has been done across the university that addresses the way these tools are being used by lecturers and the lecturers' perceptions of their use. The literature within the South African context is also very scant. It is in this context that this article is written and attempts to address whether rubrics inform the lecturers' teaching practice and whether rubrics assist in curriculum development and review.

\section{The research process}

This research was conducted by means of a lecturer questionnaire, the overall aim of which was to assess the value that assessment rubrics have for the lecturer/assessor. The questionnaire was first piloted with a group of five lecturers. The focus of the pilot was to establish whether the questions were eliciting the responses they were intended to obtain. The responses received from the pilot were used to modify some of the questions. A total of 40 lecturing staff completed the revised questionnaire. These lecturers were from the faculties of Arts, Community and Health Sciences, Dentistry, Economic and Management Sciences, and Natural Sciences. The questionnaire was disseminated in the following two 
ways: The researcher approached lecturing staff that she knew either personally or via email and enquired if they would be willing to participate. In addition, the questionnaire was emailed to the Teaching and Learning Specialist in each faculty for dissemination to lecturing staff in their faculty. Staff were requested to email the completed questionnaire directly to the researcher or to their Teaching and Learning Specialist.

Of the 40 lecturers that completed the questionnaire, 12 were males and 28 females. Sixteen of these lecturers only taught first year students while the others taught across the different levels with nine of them teaching at post-graduate level. The subjects they taught varied from Auditing, Business Ethics, Computer Science, Language Learning and Design, Political Studies, and Sports Psychology and Management.

The questionnaire itself consisted of biographical data (e.g. teaching subjects, level of teaching, teaching experience, etc.) as well as a combination of open and closed questions which focused on the design of the rubric (e.g. How do you construct your rubric? Please explain), its use (e.g. Do you go through the rubric with students before you use it? Explain; Do you think the rubric benefits the student? Explain), and its value to the lecturer (Does the rubric help you reflect on your teaching practice?; Does the rubric assist you in curriculum review and development? Explain). The responses to the yes/notype questions were listed and then counted (see Appendix 1) whereas the open-ended questions were first grouped into three broad categories, that is, the design and use of the rubric, its benefits for students and its benefits for the lecturer/assessor, with a particular focus on the role that rubrics play in informing one's teaching practice, and curriculum review and development. The data for each category was analysed by searching for patterns as well as similarities and differences in responses. These were then recorded and grouped into workable themes.

\section{Findings}

The three broad categories of the findings, i.e. the design and use of the rubric; its value for students; and its value for the lecturer/assessor are discussed below. Some of the challenges experienced by lecturers are also discussed.

\subsection{The rubric design and use}

Assessment in higher education involves a range of assessment types depending on the subject, content and what is being tested. As such, lecturers reported that they use a variety of assessment tasks ranging from essay questions, multi-layered questions, specific topic point questions, portfolios, etc. All except three lecturers reported that they make use of assessment rubrics for their major assessment tasks. A few lecturers elaborated by saying that their courses consisted of many 'little' tasks and therefore it was not possible to create a rubric for every task, hence they focused on the tasks with higher weightings.

Approximately 50\% of the lecturers stated that students are given the rubric together with the assessment task. Majority of the others stated that it forms part of their course reader and students are alerted to it either at the beginning of the course or when the assignment topic is discussed. To this end, rubrics given to students prior to the commencement of an assignment is beneficial as it helps direct them towards the research needed to complete the task and to stay focused on the task. This in itself may improve the quality of the work produced (Bolton 2006; Schneider 2006). These researchers argue that the sole purpose of a rubric should not be just for grading but it should be used as an instructional tool. 
Only $62.5 \%$ of the lecturers indicated that they go through the rubric with students and their reasons revolved around providing clarity on the assignment task; to make the lecturers' expectations explicit; to give students an idea of what is being assessed; and to provide clarity on how marks are allocated. Some responses for not going through the rubric with students included 'It is self-explanatory and can be found in their [students] study guides'; and '... only with the first assignment and after that I feel that students should understand what the expectations are'. The lecturer who said that she only sometimes discussed the rubric with students explained:

... so that they know what they need to aim for BUT there are also dangers with this, as rubrics can generate within students a very fragmented, and formulaic approach to writing. I can always tell which students/which tasks have made use of rubrics. They are often the more boring ones.

This point on rigidity was also mentioned as a challenge experienced by a few lecturers when designing the rubric. For example, one lecturer stated:

... sometimes rubrics are too rigid and don't allow students creativity and learning outside of what is in the rubric. Sometimes the marking scale used does not allow you to credit or discredit a student in certain criteria as their performances is not specifically in that area.

Another lecturer who expressed a similar view elaborated by saying '... I try to create the rubric so that it is structured enough for me to assess important aspects of the task, but vague enough to allow new insights or changes in direction'.

With regards to the construction of the rubric, while many lecturers reported that they customize a generic rubric to suit the 'outcomes of their task' or 'modify existing rubrics to suit the assignment', there were some lecturers who stated that they used a generic rubric for all their writing tasks. As stated earlier, having a clear idea of the learning outcomes and the criteria for measuring the outcome are essential for the creation of a good rubric.

\subsection{The value of rubrics for students}

Majority of the lecturers were in agreement that rubrics were beneficial to the student while some lecturers were less certain and wrote 'I don't know'; 'sometimes'; and 'not always'. There were varied responses for why rubrics benefited the student and these focused mostly on benefits during the pre-writing and writing stages of the assessment task, with little focus on the after writing stages of the assessment.

The lecturer who responded that rubrics 'maybe' beneficial, stated 'I do think it can clarify my expectations, but unless students are really familiar with academic writing - and mine are first years so they aren't yet - I wonder if they really do pay attention or find it helpful'. In this regard, McKenna $(2007,26)$ argues that the 'assessment rubric alone cannot make overt all the subtle expectations of higher education' especially with students who do not have the 'metadiscourse of education'. For these students the 'use of criterionreferenced assessment rubric can go at least some way towards making tacit, hidden norms more accessible to all'. The lecturer who stated that rubrics are 'not always' beneficial clarified by stating 'Increasingly I find that students' performances are related less to what is going on in a module, and more to their socio-economic circumstances. It is however important, I think, to maintain the rubric as definitions of minimum standards.' It must be noted that, many of the students that attend this university come from lower socio-economic backgrounds which burdens them with many challenges. A significant number of them struggle to cope academically (Bharuthram 2012). While the 
rubric is created with good intentions, it sometimes falls by the wayside with such students in that they just do not use it or they function well below the levels of performance required to exploit the rubric. However, as acknowledged by the lecturer this is no reason to discard the rubric and the rubric criteria could be used to reflect the minimum threshold level that students should reach to qualify for a particular grade.

\subsection{The value of rubrics for the assessor/lecturer}

All lecturers were in agreement that the rubric benefitted the lecturer/assessor. Most of their explanations revolved around the fact that rubrics helped to make marking more objective; speed up the marking process; standardize marks and ensures transparency. Only three lecturers focused on the fact that the rubric helps them think about what it is they expect from students and where they need to improve or change their teaching approach. The fact that most lecturers focused on the rubric as a grading tool highlights the importance of alerting them to the instructional value of rubrics. In opposition to making marking more objective, one lecturer wrote

that while the 'rubric is helpful' ... 'much can get lost in between' and it 'does

not guarantee objective marking'. While the rubric may not guarantee objective marking, it is a tool that, if designed and used properly, can play a role in minimizing subjectivity especially when there are multiple markers.

The rubric as a reflective tool: teaching practice and curriculum review and development Only $35 \%$ of the lecturers stated that rubrics help them reflect on their teaching practice. For example, one lecturer stated that '... it provides some sort of framework on which I can base my lectures and it helps me reflect on the outcomes of each lecture and adapt my teaching style accordingly'. This point is also articulated by Reddy and Andrade (2010, 441) who state that rating students work by means of a rubric 'enabled an instructor to pinpoint the areas of weakness and thereby identify needed improvements in the instruction'. Another lecturer stated that the rubric helps:

... when one looks at what is expected of students. You also have to review what you have presented to them and how this was done. A rubric helps you identify problem areas if for example a group experienced the same problem or did very well. You can then review how this aspect was presented and to what extent it supported or did not support the student. Issues around the timing of the assessment task are also highlighted in terms of the readiness of the student to engage/perform.

This lecturer uses the rubric as a feedback tool. On the basis of students performance she is able to make judgements about the content that she presented as well as the way it was presented. In addition to this, the rubric is used as a tool to inform her of students readiness for the content presented. However, this view was shared by less than half of the lecturers as illustrated by one lecturer who felt that the rubric is more 'aligned to provide structure for the students and from this they are assessed accordingly. It therefore doesn't specifically look at the teaching practice'.

Only $30 \%$ of the lecturers articulated that rubrics assist them in curriculum review and development. Majority of these lecturers stated that they used the rubric as a reflective tool when assessing the progress of the course. One lecturer elaborated further by saying 'It also helps with the setting of 'standards', and it allows one to compare the task, its outcomes, and the results with that of a different course' and 'the rubric does draw your attention to aspects of the content that needs to be illuminated or reviewed'. Twenty-five per cent of the lecturers indicated the rubric does not assist them in curriculum review and development while the others were doubtful. Some lecturers stated that it is the 
course evaluations that students complete at the end of the semester or year that helps them in curriculum review and development rather than the rubric.

\section{Challenges experienced by lecturers when using rubrics}

A few lecturers listed some challenges that they experienced with rubrics. Some of these challenges related to the assigning of marks as per the criteria listed in the rubric. As an illustration, one lecturer wrote 'if a rubric is not detailed enough and does not give a range of marks per criteria it is difficult to judge more specifically what a task is worth' and another stated 'When I weigh marks I often find that the mark I arrive at when I add up each section in the rubric is not the mark I have in my head - so there's something that goes into marking that a rubric can't capture'.

Another lecturer felt that although rubrics have the potential to speed up the marking process she still finds herself giving extensive feedback in the text. It must be noted that this lecturer teaches on the foundation programme. The foundation students are identified as students requiring extra assistance and are therefore placed in a programme that gives them an extra year to complete their degree. While the design of the rubric may capture the explicit levels of performance as per the lecturers' expectations of the task, depending on the needs of the particular group of students, it may still not be adequate to capture/cater for all the 'gaps' that the students sometimes encounter and hence the need for additional feedback.

Other challenges included the fact that the rubric is time consuming to construct. Some lecturers were not certain whether it was worth the effort because they were not sure whether students actually made use of it. Interestingly, this comment came from the lecturers who did not discuss the rubric with students but merely inserted them in their course reader or simply handed them out to students for use.

Some of the lecturers who have been teaching for $16+$ years were less favourable in their responses to the use of rubrics and felt that it is a useful tool for younger lecturers and those with less experience. In this regard, of importance is the fact that the rubric is a useful tool to make the lecturers' expectations explicit for the student. It is also a useful tool to guide students through their assessment tasks. As such, teaching experience should not be the determining factor in lecturers using rubrics. Additionally, the type of reading and writing done from one year of study to the next requires more expertise and critical thought. Hence, there is a need for continued support which a well-designed assessment rubric can provide.

\section{Discussion}

The findings show that while most of the lecturers who participated in this study make use of assessment rubrics, the way the rubric is designed and used by some of them is of concern. Although most of them articulated, in some way or the other, that there was alignment between their assessment tasks, the objectives of the tasks and their teaching methods and this informed the design of the rubric, there were some lecturers who made use of a generic rubric for all their assessment tasks. Noting that one of the functions of an assessment rubric is to make clear the discipline specific assessment norms of the task, it is crucial that a rubric be developed for each task (McKenna 2007, 22). While existing rubrics could be used as a starting point to develop one's own (Gibson 2013; McKenna 2007), it is important to ensure that there is a match between the assignment and its objectives. Furthermore, from the findings it seems that each lecturer takes sole responsibility of designing his/her own rubric without consultation with colleagues. Researchers (see for example, Gibson 2013; Gezie et al. 2012), suggest that prior to use 
with students the rubric should be reviewed by colleagues. They also suggest that if there are multiple assessors then there should be a calibration process. In these sessions assessors come to a shared understanding of the rubric. None of the participants addressed this point in the findings.

The findings also suggest that some lecturers believe that merely providing students with a rubric without unpacking the rubric or having discussions on how the rubric could be used is sufficient. This could imply that these lecturers are unaware of the many benefits of the rubric, in particular, that the rubric is more than a grading tool and has instructional value, and/or they use the rubric just to satisfy assessment requirements. Lecturers need to be made aware that rubrics are not entirely self-explanatory and sometimes students may find the rubric confusing and may therefore not feel comfortable using it (Gezie et al. 2012). Hence, in order for students to obtain maximum benefit from the rubric, it must be explained to them (Andrade 2005). In addition, one way of attaining student investment in the rubric is by discussing it with them and teaching them how it could be used as a reflective tool. Additionally, researchers (Allen and Tanner 2006; Gibson 2013) suggest co- designing the rubric with students.

While many of the lecturers articulated that rubrics assist students in planning and preparing appropriately for a task, the findings show that only a handful of them viewed the rubric as a valuable student feedback or self-assessment tool. Yet, research has shown that with the help of the rubric students are able to review their end product and know exactly where their strengths and weaknesses lie (Gibson 2013) and hence improve their performance on their own (Andrade and Du 2005). In other words, rubrics can lead to the development of self-assessment which Wiggins (1991) views as inseparable from any assessment task that is aimed at improving learning. Furthermore, when students repeatedly practice self-assessment they become more able to spot errors in their own work and it could increase their sense of responsibility for their own work (Andrade n.d). However, for maximum benefit it is important that students receive appropriately guided practice on how to use the rubric to assess themselves, their peers, and/or for revision purposes.

In the findings, some lecturers raised the concern that the rubric can be very formulaic and rigid and students may only strive to meet the levels of performance as laid out in the rubric and nothing more, thus having a negative impact on learning.

This has also been expressed in the literature on rubrics (see for example, Galloway n.d.; Gunning 2007). To this end, Strouthopoulos and Peterson $(2011,52)$ discuss how some of these concerns could be overcome. In particular, in addition to the core/ fundamental elements of the rubric, they suggest using a list of extra criteria which they refer to as 'a customizable list' to capture the less tangible aspects of the task. In this way, the element of creativity need not be lost but can be factored into the rubric design (Strouthopoulos and Peterson 2011). Furthermore, when students are novices to a particular task or type of writing then one has to weigh the benefits of using the rubric against its weaknesses.

While less than half of the lecturers articulated that the rubric assists them reflect on their teaching practice or review their curriculum, it must be noted that the rubric is more than a tool that provides students with some kind of structure for their assessments and is not only effective for measuring, evaluating and reporting student performance. The rubric can also guide 'students' learning, teachers' instruction, course development and administrators' program observations' (Reddy 2007, 4). As indicated by the lecturer quote in the finding, the rubric could be used to inform the lecturer, through the performance of the students, whether the outcomes of a particular task have been met. This implies that should the expected outcomes not be met by most of the students then this could be an 
indication that the lecturer needs to reflect on his/her teaching practice and make revisions accordingly. However, for the rubric to inform the process of making improvements to courses and instruction' the rubric must be clear, valid and reliable once again stressing the need for a well- designed rubric (Reddy and Andrade 2010, 441).

With regards to the challenges experienced by lecturers, the discrepancies in allocating marks using rubrics as reported by some lecturers has been addressed by Sadler (2009). These are listed by Sadler (2009) as anomalies in his discussion of analytical grading (where each pre-set criteria for a particular task is given a mark and these marks are then totalled to form the final mark) and holistic grading (where while there may be pre-set criteria the assessors make an overall judgement in accordance with the set criteria). Sadler $(2009,165)$ reports that even experienced assessors found discrepancies between their global and analytic assessing whereby work judged as outstanding overall may not rate as such on each criteria. Similarly, the overall judgement may be mediocre yet each criterion may be judged as being good. According to Sadler (2009), these discrepancies may arise when an identified criterion is not included in the rubric or the pre-set criteria are not clear. This once again suggests that much thought needs to go into the construction of the rubric and that the rubric should be reviewed by colleagues before use.

\section{Conclusion}

This article highlights the perception that a group of lecturers have on the value of assessment rubrics for both the assessor and the student. While most of the participants have some knowledge of Biggs (1996) notion of 'constructive alignment' which seems to foreground their construction of the rubric, it appears that most of them view the creation of a particular rubric as a once off task and not as a fluid and recursive process (Gibson 2013). As mentioned in the discussion, researchers suggest that the rubric should be reviewed by many colleagues as possible and that the lecturer should be willing to modify the rubric even during the grading process in order to cater for unanticipated responses from students.

Of concern is that many lecturers are unaware of the numerous benefits that rubrics have for the student and the lecturer. While most of them are aware that rubrics help students in their preparation of the assessment task and keep their focus, the important role of the rubric as a feedback and self/peer assessment tool was not acknowledged. Feedback is integral to the learning process and the rubric can be an effective tool for fulfilling this role (Lombard 2011). The rubric could also be used as a self/peer assessment tool. It is important that students learn to understand what 'constitutes quality' and they also need to know how to evaluate quality (Sadler 2009, 178). This can be achieved by teaching them how to self and/or peer assess which could also lead to deeper engagement with the rubric which in turn could lead to deeper learning and higher academic achievement by students (Reddy and Andrade 2010).

The role that rubrics can play in informing one's teaching practice and in curriculum review and development was articulated by some of the lecturers, albeit a few, who stated that by examining student scores on the rubric they were able to identify areas of strengths and weakness and make improvements to their teaching methods. Others stated that the mere act of examining the outcomes of the task in relation to the module/programme in order to construct the rubric assisted them in noting gaps or overlaps in the module and this process leads to review of the curriculum. However, they were in the minority. Many of the remaining lecturers did not acknowledge the important role that rubrics can play in informing one's teaching practice and in curriculum review and development. It would seem that they tend to rely solely on the feedback provided by students in the end of semester/year course evaluations. Thus, the overall impression 
obtained from this study is that because many of the lecturers do not assign instructional value to the rubric it is used in a very mechanical fashion mostly for grading purposes.

Although this study is based on a cohort of 40 participants, one can conclude that since the rubric is not a tool that is generally discussed in open conversations between academics nor has it been discussed in teaching and learning platforms at the institution, the responses of the other staff would be similar. It is therefore recommended that university wide seminars/workshops be held for staff on the use of rubrics specifically focusing on the design of rubrics, including student participation in the design, and the multiple benefits of rubrics for both the lecturer and the student. Here, a pivotal role has to be played by the faculty based Teaching and Learning specialists. This study also suggests further research into the area of the value of rubrics for informing one's teaching practice and curriculum review and development. Additional areas of research suggested include the value of rubrics as a self/peer-assessment and evaluation tool and the value of co-constructing rubrics with students.

\section{Notes on contributors}

SHARITA BHARUTHRAM is a senior lecturer in the Department of English, University of the Western Cape. She obtained her PhD in 2007 in the field of Applied Linguistics from the University of KwaZulu-Natal, Durban. She currently co-ordinates and lectures an academic literacies programme that is offered to students from the Faculty of Community and Health Sciences. 


\section{References}

Allen, D. and K. Tanner. 2006. Rubrics: Tools for making learning goals and evaluation criteria explicit for both teachers and learners. Life Science Education 5(3): 197- 203.

Andrade, H. G. n.d. Understanding rubrics. Available at: http://learnweb.harvard,edu/alps/thinking/docs/rubicar.htm (accessed 10 August 2014).

Andrade, H. G. 2005. Teaching with rubrics: The good, the bad, the ugly. College Teaching 53 (1): $27^{-} 30$.

Andrade, H. and Y. Du. 2005. Student perspectives on rubric-referenced assessment. Practical Assessment, Research and Evaluation 10 (3). Available at: http://pareonline.net/pdf/v1on3pdf (accessed 10 August 2014).

Andrade, H. L., Y. Du and K. Mycek. 2010. Rubric-referenced self-assessment and middle Students' writing. Assessment in Education: Principles, Policy and Practice 17 (2): 199214 .

Arter, J. and J. Chappuis. 2007. Creating and recognizing quality rubrics. Upper Saddle River, NJ: Pearson/Merrill Prentice Hall.

Bharuthram, S. 2012. Making a case for the teaching of reading across the curriculum in higher education. South African Journal of Education 32(2): 205- 214.

Biggs, J. B. 1996. Enhancing teaching through constructive alignment. Higher Education 32(3): $347^{-} 364$.

Biggs, J. B. and C. Tang. 2009. Applying constructive alignment to outcomes-based teaching and learning. Available at: https://intronet.tudelift.nl/.../What-isConstructiveAlignment.pdf (accessed 23 April 2015).

Bolton, C. F. 2006. Rubrics and adult learners: Andragogy and assessment. Assessment Update 18 (3): $5^{-} 6$.

Chapman, V. G. and M. D. Inman. 2009. A conundrum: Rubrics or creativity/metacognitive development? Educational Horizons 87(3): 198- 202.

Cooper, B. S. and A. Gargan. 2009. Rubrics in education, old term, new meanings. Phi Delta Kappan 91(1): 54-55.

Gallavan, N. P. and E. Kottler. 2009. Constructing rubrics and assessing progress collaboratively with Social Studies students. The Social Studies 100(4): 154-158.

Galloway, J. P. n.d. The value and perception of rubrics in teacher education. Available at: http://tech.jerrygalloway.com/support/Rubric ppr V2pdf (accessed 10 August 2014).

Gezie, A., K. Khaja, V. N. Chang, M. E. Adamek and M. B. Johnsen. 2012. Rubrics as a tool for learning and assessment: What do Baccalaureate students think? Journal of Teaching in Social Work 32 (4): 421-437.

Gibson, B. D. 2013. Grading rubrics: Their creation and their many benefits to professors and students. From the selected works of B.D. Gibson. Available at: 
http://works.bepress.com/cgi/viewcontent.cgi?article=1000\&content=brendagibson (accessed 10 August 2014).

Gunning, T. 2007. Creating literacy instruction for all students, sixth edn. Upper Saddle River, NJ: Pearson.

Lombard, B. J. J. 2011. Revisiting the value of rubrics for student engagement in assessment and feedback in the South African University classroom. The Journal of Transdisciplinary Research in Southern Africa 7 (2): 367-382.

Lombardi, M. M. and D. Oblinger. 2008. Making the grade: The role of assessment in authentic learning. Educase Learning Initiative. Available at: http://iun.edu/online/docs/EL13019pdf (assessed 10 August 2014).

McKenna, S. 2007. Assessment rubric as a means of making academic expectations explicit. The Journal of Independent Teaching and Learning 2: 22-30.

Owens, K. R. 2005. Book review: A review of introduction to rubrics: An assessment tool to save grading time, convey effective feedback, and promote student learning. Community College Journal of Research and Practice 30 (1): 72-74.

Reddy, M. 2007. Effect of rubrics on enhancement of student learning. Educate 7 (1): 327. Reddy, M. and H. Andrade. 2010. A review of rubric use in higher education. Assessment and Evaluation in Higher Education 35 (4): 435-448.

Sadler, D. R. 2009. Indeterminacy in the use of preset criteria for assessment and grading. Assessment and Evaluation in Higher Education 34 (2): 159-179.

Schneider, J. F. 2006. Rubrics for teacher education in community college. Enterprise 12 (1): 39-55.

Strouthopoulos, C. and J. L. Peterson. 2011. From rigidity to freedom: An English Department's journey in rethinking how we teach and assess writing. Teaching English in the Two-Year College 39 (1): 43-62.

Wiggins, G. 1991. Standards, not standardization: Evoking quality student work. Educational Leadership 48 (5): 18-25.

Wilson, M. 2006. Rethinking rubrics in Writing Assessment. Portsmouth, NH: Heinemann. 


\section{APPENDIX 1}

Table of results for closed questions

\begin{tabular}{|c|c|c|c|c|c|c|}
\hline \multirow[t]{2}{*}{ Question } & \multicolumn{2}{|l|}{ Yes } & \multicolumn{2}{|l|}{ No } & \multirow[t]{2}{*}{ Uncertain } & \multirow[t]{2}{*}{ Total } \\
\hline & Number & $\%$ & Number & $\%$ & & \\
\hline $\begin{array}{l}\text { Do you provide your } \\
\text { students with rubrics? }\end{array}$ & 37 & 92.5 & 3 & 7.5 & & 40 \\
\hline $\begin{array}{l}\text { Do you use a generic rubric } \\
\text { for all assessment tasks? }\end{array}$ & 8 & 20 & 32 & 80 & & 40 \\
\hline $\begin{array}{l}\text { Do you design a rubric for } \\
\text { each assessment task? }\end{array}$ & 37 & 92.5 & 3 & 7.5 & & 40 \\
\hline $\begin{array}{l}\text { Do you go through the rubric } \\
\text { with students before they } \\
\text { use it? }\end{array}$ & 25 & 62.5 & 15 & 37.5 & & 40 \\
\hline $\begin{array}{l}\text { Do you think the rubric } \\
\text { benefits the student? }\end{array}$ & 35 & 87.5 & & & 5 & 40 \\
\hline $\begin{array}{l}\text { Do you think the rubric } \\
\text { benefits you the assessor? }\end{array}$ & 40 & 100 & & & & 40 \\
\hline $\begin{array}{l}\text { Does the use of the rubric } \\
\text { help you reflect on your } \\
\text { teaching practice? }\end{array}$ & 14 & 35 & 26 & 65 & & 40 \\
\hline $\begin{array}{l}\text { Does the use of the rubric } \\
\text { assist you in curriculum } \\
\text { review and development? }\end{array}$ & 12 & 30 & 10 & 25 & 18 & 40 \\
\hline
\end{tabular}

